\title{
Gómez Álvarez Cristina y Tovar y de Teresa, Guillermo (2009) Censura y revolución. Libros prohibidos por la Inquisición de México (1790-1819). Madrid: Trama editorial-Consejo de la Ciudad de México.
}

Mariana Ozuna Castañeda

FFyL-UNAM

Durante el año 2010 México conmemora el inicio del movimiento insurgente que encabezó Miguel Hidalgo y Costilla, el programa de festejos que ha preparado el gobierno mexicano se manifiesta en todos los niveles, lo mismo con estudios especializados, mesas redondas, ediciones conmemorativas, trabajos de rescate - que se expresan por radio, impreso y televisión-, que en la difusión del conocimiento histórico y cultural. El libro Censura y revolución merece una apreciación crítica justamente en el marco del movimiento de Independencia y no en el marco de los festejos. Esta reflexión se desprende de que el libro se publicó un año antes de los festejos, con lo cual queriéndolo o no, se distancia y distingue de las múltiples publicaciones que saturan, comprensiblemente, el espacio público actualmente.

El libro que reseñamos indaga sobre la relación entre dos nociones, por un lado la censura como manifestación del poder absoluto y despótico de la Corona española, por otro la cultura política que promovió la revolución de independencia. Ambas nociones se estudian en sus representaciones de la época: la Inquisición como institución encargada de llevar a cabo la labor censora y el libro o impreso en general, vehículo de ideas y mercancía cultural. El periodo de estudio es 1790 a 1819, marcado por el interés de ubicar justamente las acciones que tomó la Inquisición para controlar la influencia de las ideas emanadas de la Revolución francesa. No es casual, pues esta periodización, muy al contrario se propone reflexionar sobre uno de los presupuestos de la historiografía tradicional: que el conocimiento que tuvieron Hidalgo, Morelos y los insurgentes en general de las ideas de los conocidos como "filósofos franceses" —Voltaire, Rousseau, Montesquie- fue la inspiración para emprender la Revolución de Independencia en la Nueva España. Entre otras muchas aportaciones Censura y revolución matiza a tal punto este presupuesto que termina por transformarlo profundamente.

El estudio de la censura de la época desde el enfoque cultural que Censura y revolución propone no tiene antecedentes en México ni en España. Los autores no sólo describen el funcionamiento de la institución censora - funcionarios, instancias, jurisdicciones, motivos de la censura-, asunto ya apasionante, sino 
que esto se encamina a analizar los documentos en los que se plasmaba la censura, es decir, los edictos. Estos pliegos daban a conocer los títulos prohibidos, los tipos de prohibición y las penas a que se exponían quienes poseían o leían libros prohibidos. De suerte que se revelan como una fuente rica para el estudio de la circulación de lo prohibido, pero sobre todo, dan indicios confiables acerca de la mentalidad de los inquisidores. Ahora bien, los edictos analizados en el libro forman parte de las acciones emprendidas por la Inquisición española durante el periodo convulsivo que comprende la Revolución francesa (1789), la invasión napoleónica a España (1808), con el consecuente desarrollo del liberalismo que se practicó en la Corte de Cádiz (1812), sus importantes consecuencias tanto en la metrópoli como en los territorios ultramarinos y, por supuesto, la insurgencia en la Nueva España (1810-1813). Es decir, los edictos se analizan en virtud de la valiosa información que proporcionan sobre el tránsito de las ideas que se percibían como amenazantes para el Antiguo Régimen. Con todo, la obra no se detiene ahí.

Para conocer el peso verdadero que tuvo la Inquisición y su actuar censor para impedir y controlar la circulación de las nuevas "peligrosas" ideas, se hace necesario enmarcar su quehacer en el ámbito del comercio del libro: ¿cuál era el volumen de libros e impresos que se imprimía, circulaba, comerciaba -legal e ilegalmente-, traducía y que la Inquisición debía observar? Los autores muestran que el tráfico legal de libros de Europa a la Nueva España tuvo un crecimiento de 1750 a 1818, cuyas altas y bajas explican someramente. A la luz de este fenómeno comercial, la labor de la censura es susceptible de una mejor valoración, pues como demuestran los autores no sólo es una cuestión de volumen de impresos en circulación, sino de la aceleración del comercio que rebasaba por mucho los ritmos y tiempos de operación de la Inquisición; a esto la investigación agrega que los edictos que buscaban amedrentar a la sociedad, paradójicamente, le proporcionaban una lista de novedades prohibidas, esto es, eran el vehículo mismo de promoción de las ideas que combatían. ¿Y qué ideas eran esas?, ¿qué impresos eran esos?

Se trataba de la oleada del pensamiento moderno, de la llustración. Censura y revolución acuña una idea más vasta para comprender el pensamiento ilustrado, no se trata de la filosofía moderna strictu sensu, ha de comprenderse en el amplio sentido de divulgación de las nuevas ideas, esto implica incluir una serie de temas y productos editoriales, tales como los diccionarios, los manuales de artes y técnicas para artesanos, la literatura libertina o pornográfica, las gramáticas, poéticas y manuales de estilo; y considerar aspectos que acompañan el auge comercial, como son: el incremento en el comercio de obras de literatura (comedias y obras en prosa la presencia de formatos diversos (folletos, libros, periódicos, hojas volantes), o bien considerar que el fenómeno de la traducción es parte de la expansión y 
adapatación del pensamiento moderno. Desde esta óptica, las obras modernas perseguidas son contrapuestas a la presencia del libro religioso o de devoción que iba perdiendo terreno frente a las obras seculares. Así, los edictos de la censura muestran el amplio abanico de contenidos y de veneros del pensamiento que se adentraban por la geografía novohispana, para los cuales los diques de la Inquisición fueron insuficientes, como se concluye en el estudio: "El Santo Oficio fue el brazo censor de la Corona española y nunca obró con autonomía; nació y murió con el absolutismo [...] La censura ejercida por el Santo Oficio durante el periodo estudiado fue un completo fracaso". (139)

Descuella en el libro por su oportunidad histórica, lo dedicado a la insurgencia mexicana, pues durante el periodo que va de 1810 a 1815, la censura represora se concentra en combatir la revolución iniciada por Miguel Hidalgo y que, tras su aprensión y muerte, continuará. Censura y revolución ofrece al lector el análisis de la circulación y penetración de los documentos insurgentes a la luz de sus condiciones materiales; los documentos del movimiento revolucionario ponen en evidencia la relación entre el manuscrito y el impreso. Dado que el ejército revolucionario no tenía a su servicio imprentas como sí lo sucedía con el gobierno realista, el manuscrito resultó ser uno de los medios de difusión de los comunicados, manifiestos y propaganda del ideario insurgente, muchas veces el impreso fue transcrito, poniendo al manuscrito al servicio del impreso en una circunstancia precaria para la impresión. Y es gracias a los edictos de la Inquisición mexicana, que se cuenta con la descripción no sólo de los títulos de los documentos sino con síntesis de sus contenidos, lo que deja traslucir la mentalidad de los censores.

Por otra parte, al lector le resultará novedosa esta dimensión impresa y escrita del proceso revolucionario preocupado por dar a conocer no sólo sus motivaciones, sino su programa político y social — caso del Decreto Constitucional para la Libertad de la América Mexicana, emanado del Supremo Gobierno Mexicano en el año de 1814, mejor conocido como Constitución de Apatzingán-en los términos de la cultura política moderna, muestra el deseo constante de los insurgentes a lo largo de los años de guerra de erigir un nuevo gobierno.

Para el Generalísimo de las Armas Americanas, Miguel Hidalgo y Costilla este nuevo gobierno consistía en dictar "leyes que destierren la pobreza" y moderaran "la devastación del reino y la extracción de su dinero"; un gobierno a decir de la Constitución de Apatzingán que acatara lo siguiente: "La felicidad del pueblo y de cada uno de los ciudadanos, consiste en el goce de la igualdad, seguridad, prosperidad y libertad. La íntegra conservación de estos derechos es el objeto de la institución de los gobiernos y el único fin de las asociaciones".

Es en este sentido que Censura y revolución parece distanciarse de los actos de conmemoración de 2010, pues la envergadura de la investigación que lo sustenta se funda en preguntar desde otro ángulo para evitar la repetición de supuestos históricos. El examen de la censura, de la institución inquisitorial 
metropolitana y mexicana, de la temática de los impresos consignados en los edictos, están guiado por un afán crítico a partir del cual se invita a interrogarnos sobre la herencia revolucionaria más profundamente. Este afán da con hallazgos que requieren nuevos trabajos: se sugiere que el historiador debe atender más al papel que tuvo la literatura, en especial las comedias, en la circulación de los valores ilustrados y la promoción de nuevas sociabilidades; o bien ponderar el hecho de que la Inquisición persigue exclusivamente la producción impresa que va de Europa a Nueva España sin prestar atención a la producción y circulación de impresos americanos. Esto último revela de qué manera pensar que los movimientos de emancipación son hijos o efectos de la Revolución francesa.

Las gráficas, cuadros, el análisis de las cifras ahí contenidas pone otro tipo de evidencia ante el lector, invitándolo a comprender y aprehender los procesos históricos desde un ángulo más material; de suerte que la obra se aleja del discurso de interpretación histórica para proponer un discurso científico, ya que genera nuevo conocimiento partiendo de un método que él mismo propone. A pesar de esto, el estilo del libro es accesible y no es sólo en lo textual que la obra agradará al lector que desee conocer algunas aristas de libro prohibido en la época revolucionaria, en términos editoriales el volumen es ligero e incluye ilustraciones de las portadillas de muchísimos de los impresos prohibidos, de suerte que el lector puede asomarse a esta cultura material ahora lejana; el cuidado editorial y los detalles - como el colofón- expresan la estupenda factura de la obra.

Además, la investigación está acompañada del catálogo reconstruido de los libros prohibidos por los edictos estudiados. Gracias a esto, el libro ofrece una fuente de primera mano para conocer no sólo los motivos de censura, sino los datos completos de los materiales (lengua, casa editorial, características de la edición, lugar de edición, formato). El catálogo puede leerse con la curiosidad del bibliófilo o del simple interesado en la cultura letrada perseguida, o bien fungir como herramienta para el investigador o estudiante que se decida a continuar por los senderos de la historia del libro, la historia cultural o intelectual de la época de la revolución de Independencia en nuestro país.

Las ideas por sí mismas no hacen revoluciones, y si bien lo prohibido fue parte del pensamiento de la época, convivió con el pensamiento vigente y aceptado. Las ideas - se dice en Censura y revolución - transitan por procesos de adaptación a las circunstancias político-sociales de los sujetos que las piensan; las "nuevas" ideas no sustituyen a las "viejas", sino que establecen sutiles relaciones de negociación. Las páginas de este libro se esmeran por generar conocimiento histórico sólido que nos permita, más que sólo conmemorar, comprender el proceso que condujo a individuos como Miguel Hidalgo, José María Morelos, Ignacio López Rayón, José María Cos y muchos otros a respaldar con las armas sus proyectos políticos de nación, cuyas aspiraciones de prosperidad, seguridad y justicia social siguen presentes entre los mexicanos dos siglos después. 